\title{
Radio-pathologic Evaluation of Non Traumatic Low Backache in Young Adults (20-40 years)
}

\author{
Authors \\ Dr Ashish Nigam ${ }^{1}$, Dr Priya Sahu ${ }^{2}$ \\ ${ }^{1}$ Ex Resident DCA Imaging and Research Centre, 10B KG Marg, New Delhi. \\ ${ }^{2}$ Ex Resident Max Super Speciality Hospital, Saket New Delhi \\ Corresponding Author \\ Dr Ashish Nigam \\ K-40/D, Sheikh Sarai Phase II, New Delhi 110017 \\ Email:drnigamashish@yahoo.com.Mobile Number-9911764233
}

\begin{abstract}
Low backache is one of the commonest complaints encountered in clinical practice even amongst our youngsters having significant economic consequences to the affected patient, especially young employed individuals thereby leading to loss of national income by loss of labor working days. This study was aimed at evaluation of non traumatic causes of low backache in young adults with MRI lumbosacral spine and their pathologic correlation.

Keywords- Non traumatic low backache, MRI lumbosacral spine, Young adults.
\end{abstract}

\section{Introduction}

The evolution of mammals from quadrupeds to bipeds resulted in a shift in the centre of gravity and subsequent mechanical stress on the lumbar spine. The occurrence of low backache can be probably attributed to this evolution in the basic posture of human beings. In majority of the cases, acute back pain is self limited and benign with no cause identified in $95 \%$ of the patients. A 4 week followup is generally recommended as most patients with acute back pain improve in the first month after initial presentation. ${ }^{[1]}$ Imaging is commonly used for further evaluation, it should not be considered as a replacement of clinical suspicion based on an accurate history and physical exam. It is important to consider how the management will be influenced by the information obtained from radiological and pathological examinations.

\section{Aim and Objective}

The purpose of the study is to describe MRI patterns of various conditions causing non traumatic low backache in young adults and their pathologic correlation that will aid in making an appropriate diagnosis and ultimately reasonable management.

\section{Material and Methods}

This prospective study was conducted during March 2014 to March 2015. Total 1089 patients underwent MRI lumbosacral spine during the study period, out of which 221 patients of 20 to 40 years of age group were included in this study. Inclusion Criteria: All 


\section{JMSCR Vol||05||Issue||01||Page 15959-15963||January}

non traumatic cases (20-40 yrs) of low backache referred to our clinic, during the study period. Exclusion Criteria: Traumatic cases, postsurgical LS spine cases, pregnant women, patients contraindicated to MRI such as cardiac pacemaker, cochlear implants etc.

\section{Results}

Prevalence of non traumatic low back in young adults (20-40 years) is found to be $20.29 \%$ in our study. Out of 221 young adults $55.66 \%$ were male and $44.34 \%$ were female. Degenerative pathology was found in $78.73 \%$ of cases and it is the commonest pathology causing non traumatic low backache in young adults. Other common pathologies found in our study are congenital anomaly (14.48\%), sacroiliitis (10.86\%), spondylolysis $(6.79 \%)$, hematopoietic disorders (5.43\%), inflammatory spondyloarthritis (4.98\%), Scoliosis (3.62\%), vertebral haemangioma (2.26\%), and many other miscellaneous conditions shown in the table number 1 . Infectious causes were identified in 16 patients (7.24\%) Tubercular spondylitis is the most common type of spondylitis in our study, found in $6.34 \%$ cases. Pyogenic spondylitis was detected in 1 patient, which was caused by staphylococcus aureus (confirmed on microscopy). A cysticercus cyst was found in the paraspinal muscle in 1 patient. Spinal tumors are less common cause of low backache in young adults $(1.36 \%)$. In our study we found 1 extra dural tumor which was proved to be non Hodgkin's lymphoma on histopathological examination. Two intradural extramedullary pathologies were found; one was diagnosed as nerve sheath tumor on biopsy and other was arachnoid cyst.

Table 1 Prevalence of various non traumatic causes of low backache in young adults:

\begin{tabular}{|l|l|l|}
\hline Pathologies & No. & Percentage \\
\hline Degenerative & 174 & $78.73 \%$ \\
\hline Congenital anomalies & 32 & $14.48 \%$ \\
\hline Sacroiliitis & 24 & $10.86 \%$ \\
\hline Infective & 16 & $7.24 \%$ \\
\hline Spondylolysis & 15 & $6.79 \%$ \\
\hline Normal study & 14 & $6.34 \%$ \\
\hline Hematopoietic disorders & 12 & $5.43 \%$ \\
\hline
\end{tabular}

\begin{tabular}{|l|l|l|}
\hline $\begin{array}{l}\text { Inflammatory } \\
\text { spondyloarthropathy }\end{array}$ & 11 & $4.98 \%$ \\
\hline Scoliosis & 8 & $3.62 \%$ \\
\hline Vertebral haemangioma & 5 & $2.26 \%$ \\
\hline Tumor & 3 & $1.36 \%$ \\
\hline Uterine fibroids & 3 & $1.36 \%$ \\
\hline Perineural cyst & 3 & $1.36 \%$ \\
\hline Ovarian cyst & 2 & $0.91 \%$ \\
\hline Soft tissue edema & 1 & $0.45 \%$ \\
\hline osteitis condensans ilii & 1 & $0.45 \%$ \\
\hline Epidural lipomatosis & 1 & $0.45 \%$ \\
\hline Baastrup's disease & 1 & $0.45 \%$ \\
\hline
\end{tabular}

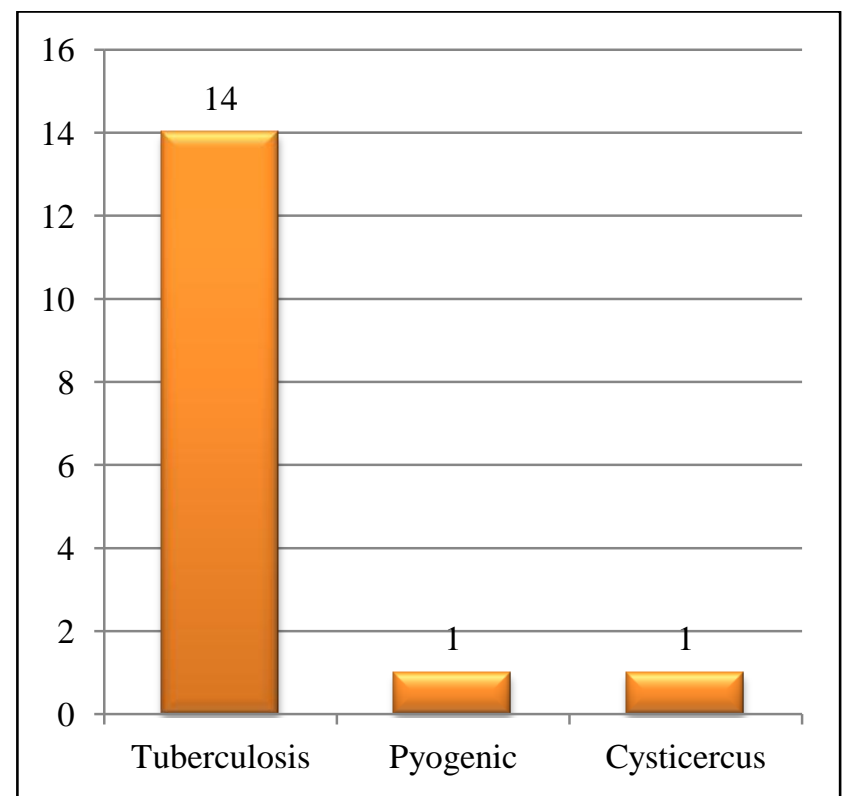

Figure 1 Graphical representation of prevalence of infective pathologies in our study.

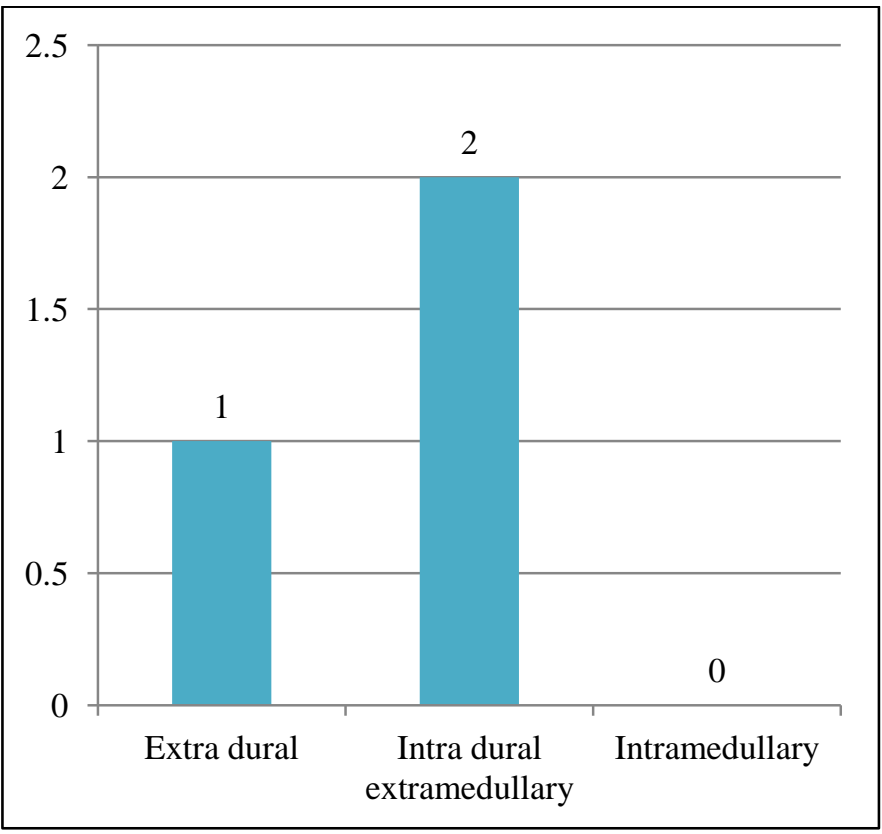

Figure 2 Graphical representation of prevalence of spinal tumors in our study. 


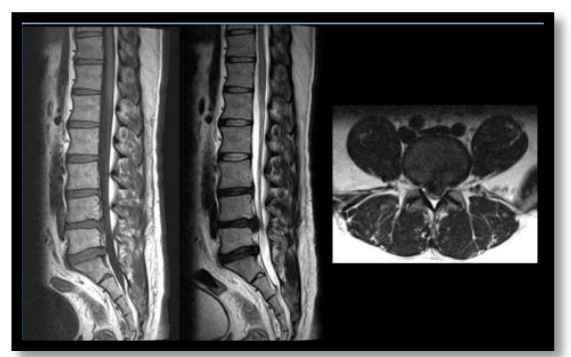

Figure 3 Sagittal T1 and T2 weighted images of LS spine displaying degenerative disc disease at L3-4, L4-5 and L5-S1 levels. The Axial T2 WI image shows posteriocentral extrusion at L4-5 level.

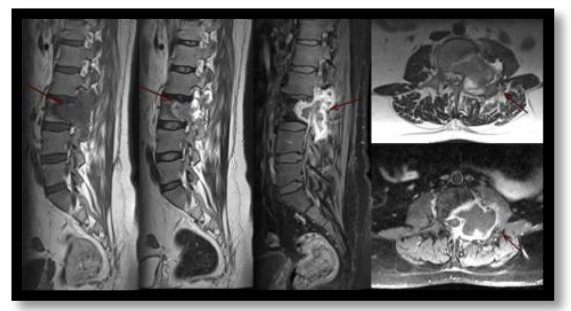

Figure 4 Sagittal and axial T1, T2 and T1 FS post contrast images display a large abscess collection in the posterolateral body of L3 vertebra invloving the left pedicle and lamina. Post contrast images show peripheral enhancement and central necrotic component.

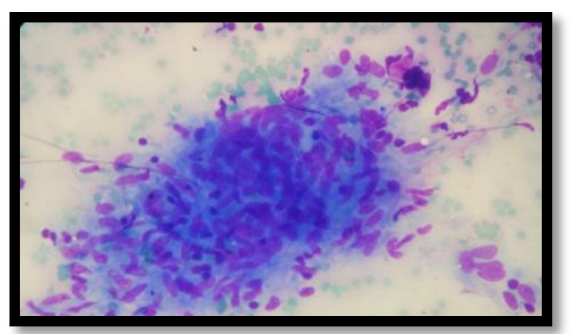

Figure 5 FNAC from left paraspinal swelling showing epithelioid granuloma. (Giemsa Stain, 40x view)

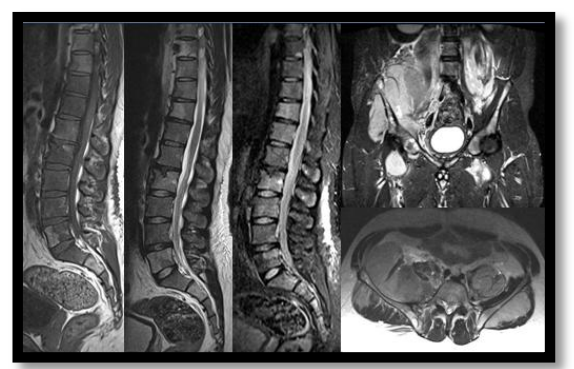

Figure 6 Sagittal T1, T2 and STIR; coronal STIR and axial T2 images of LS spine displaying Non hodgkings lymphoma, spinal and extra spinal manifestations.

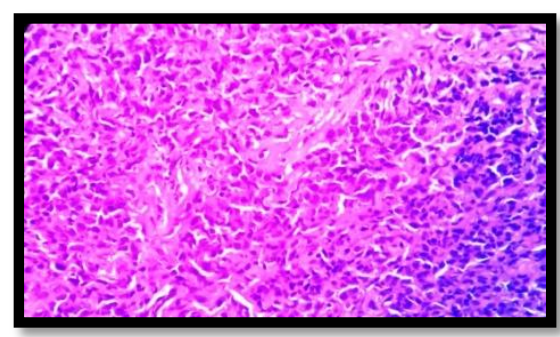

Figure 7 Biopsy from retroperitoneal mass showing atypical lymphoid population with scant cytoplasm and round nuclei. (H\&E, 10x view)

\section{Discussion}

Low back pain is a pervasive problem that affects two-thirds of adults at some time in their lives leading to work disabilities which not only imparts medical care costs but also costs of time lost from work, disability payments, and diminished productivity. The prevalence of LBP in Indian population varies between $6.2 \%$ (in general population) to $92 \%$ (in construction workers. ${ }^{[2]}$ The annual prevalence of low back pain in the United States is estimated at $15 \%$ to $45 \%{ }^{[3]}$ and the life time prevalence is over $60 \%$. ${ }^{[4]}[5]$

The role of diagnostic imaging is to provide accurate anatomic information and to affect the management decision making. [6] MRI is the investigation of choice as it has better tissue segregation and ability to show various patterns of pathologies as compared to other imaging techniques.

In our study, degenerative changes were observed in majority $(78.73 \%)$ of patients examined. Endean et. al ${ }^{[7]}$ also stated that excluding trauma, intervertebral disc abnormalities is one of the commonest cause of low back ache. However their systematic review and meta-analysis have shown that these disc changes are associated with low backache, but not specific for it. Conforti R et. al ${ }^{[8]}$ observed twentyone patients ( 9 female and 12 male) aged from 13 to 22 years for non traumatic low backache. Disc pathology was found to be most common cause. The painful symptoms exhibited at the young age of the patients suggest such pathologies as infections, tumors or malformations, but the possibility of discopathy must always be considered. Weishaupt D et. al ${ }^{[9]}$ studied MRI of lumbar spine in 
asymptomatic volunteers and found degenerative pathology as the most common cause in patients younger than 50 years, which includes disc herniations, nerve root compression, end plate abnormalities and osteoarthritis of the facet joints. The prevalence of degenerative disease in our study is relatively higher despite the younger age group, which represents changing trends of degenerative disease in young adults.

Secer $M$ et. al ${ }^{[10]}$ evaluated congenital lumbosacral malformations and neurological findings in patients with low back pain. Their study included 401 patients and congenital vertebral abnormalities were detected in 52 patients (12.1\%). Gopalakrishnan NK et. al ${ }^{[11]}$ found congenital vertebral anomalies in $9.5 \%$ of patients. In our study we detected 32 cases $(14.48 \%)$ of congenital anomalies. The variations in prevalence of spinal congenital anomalies could be explained by different age group of study populations as these pathologies are more commonly seen in the pediatric age group.

In our study sacroiliitis is found in $10.86 \%(24 / 221)$ cases. Sreedhar et. al ${ }^{[12]}$ studied 751patients of all age group, out of which $7.86 \%$ were have sacroiliitis. Schueller WC et. al ${ }^{[13]}$ demonstrated the importance of MRI in evaluation of spondyloarthritis. They suggested conventional radiography is good for the initial evaluation, but to improve the early detection of spondyloarthritis, MRI should be performed, as it enables the detection of early inflammation, such as subchondral bone marrow edema of the sacroiliac joints (SIJ), which defines sacroiliitis. In our study we found that MRI is very sensitive to detect early sacroiliitis which is represented by subarticular edema.

The infective pathology was found in 16 patients $(7.23 \%)$ in our study. Out of which 14 were diagnosed as tubercular spondylitis, 1 pyogenic spondylitis (staphylococcus aureus) and 1 paraspinal cysticercosis. Sharif HS et. al [14] evaluated the granulomatous spinal infections with MRI. MR imaging enabled diagnosis of the type of infection in $94 \%$. Jarvik JG et. al ${ }^{[15]}$ concluded that magnetic resonance imaging was the most sensitive
(0.96) and specific (0.92) test for spinal infection. In our study the sensitivity and specificity of MRI to detect spinal infections is found $93.8 \%$ and $99.8 \%$ respectively, which is strongly correlated with these studies. Hong SH et. al ${ }^{[16]}$ reported that MRI is very useful to evaluate spinal infection and to distinguish between an infection and other clinical conditions. In most cases of spinal infection, MR images showed typical findings such as vertebral endplate destruction, bone marrow and disc signal abnormalities, and paravertebral or epidural abscesses. Lee KY et. al ${ }^{[17]}$ compared the pyogenic and tubercular spondylitis. The earliest and most common radiographic finding is narrowing of the disc space in pyogenic spondylitis. In early tuberculous spondylitis, the disc space is preserved more than pyogenic spondylitis. MRI has been reported to be beneficial for early diagnosis and differential diagnosis of the spondylitis. In our study we also found all the above mentioned patterns in cases of tubercular spondylitis which very well correlated with pathological findings.

Tumors of the spine are less common cause of low backache in the age group of 20-40 years. We found only 3 tumors in our study age group two of which were intradural extramedullary and one extra dural. Gopalakrishnan NK et. al ${ }^{[11]}$ studied the causes of low back pain by MRI of 200 patients of all age group. They found the degenerative disc diseases as commonest pathology followed by congenital and traumatic lesions. Neoplastic lesions were the least common. They found only 4 cases of spinal tumors out of which 3 were extradural and 1 intradural extramedullary. Sembrano JN et. al ${ }^{[18]}$ studied the extra spinal causes of backache. They reviewed 200 cases out of which $130(65 \%)$ had spine-only pathology, whereas 50 (25\%) had extra spinal pathologies. In our study extra spinal pathologies are seen in $18.6 \%$ of cases. Such variation could be due to different objectives of the studies. The various extra spinal conditions found in our study are uterine fibroids $(1.36 \%)$, ovarian cysts $(0.91 \%)$, osteitis condensans ilii $(0.45 \%)$ and gluteal muscle pathology $(0.91 \%)$. 


\section{Conclusions}

MRI is the most useful modality in morphologic evaluation of lumbosacral spine and also correlates very well with pathologic diagnosis due to its privileged tissue differentiation ability. MRI is very helpful in early detection of various spinal pathologies as well as for treatment follow ups. Degenerative disease is the single most common category which accounts for most of the low backache in young adults for which a preventing strategy should be drafted.

\section{References}

1. Chou R, Qaseem A, Snow V, Casey D, Cross T, Shekelle P, et al. Diagnosis and treatment of low back pain: a joint clinical practice guideline from the American College of Physicians and the American Pain Society. Ann Intern Med. 2007; 147(7):47891.

2. Bindra S, Sinha AGK, Benjamin AI. Epidemiology of low back pain in indian population : A review. 2015;5(1):166-79.

3. Andersson GB. Epidemiological features of chronic low-back pain. Lancet. 1999;354 (9178):581-5.

4. Cassidy JD, Carroll LJ, Côté P. The Saskatchewan health and back pain survey. The prevalence of low back pain and related disability in Saskatchewan adults. Spine (Phila Pa 1976). 1998;23(17):1860-6.

5. Leboeuf-Yde C, Lauritsen JM. The prevalence of low back pain in the literature. A structured review of 26 Nordic studies from 1954 to 1993. Spine (Phila Pa 1976). 1995;20(19):2112-8.

6. Modic MT, Ross JS. Lumbar degenerative disk disease. Radiology. 2007;245(1):43-61.

7. Endean A, Palmer KT, Coggon D. Potential of magnetic resonance imaging findings to refine case definition for mechanical low back pain in epidemiological studies: a systematic review. Spine (Phila Pa 1976). 2011;36(2):160-9.
8. Conforti R, Scuotto A, Muras I, Cervone de Martino M, Riccio V, Bernini FP. Herniated disk in adolescents. J Neuroradiol. 1993; 20(1):60-9.

9. Weishaupt D, Zanetti M, Hodler J, Boos N. MR imaging of the lumbar spine: prevalence of intervertebral disk extrusion and sequestration, nerve root compression, end plate abnormalities, and osteoarthritis of the facet joints in asymptomatic volunteers. Radiology. 1998;209(3):661-6.

10. Secer M, Muradov JM, Dalgiç A. Evaluation of congenital lumbosacral malformations and neurological findings in patients with low back pain. Turk Neurosurg. 2009;19 (2):145-8.

11. Gopalakrishnan NK, Nadhamuni, K KT. Categorization of Pathology Causing Low Back Pain using Magnetic Resonance Imaging (MRI ). 2015;9(1):TC17-TC20.

12. Sreedhar C, Sree Ram M, Alam a, Indrajit I, Shanmuganandan K. Sacroiliitis in routine Mri for low back ache. Indian J Radiol Imaging. 2006;16(4):643.

13. Schueller WC. Inflammatory spinal disease: Spondyloarthritis : Importance of imaging. Radiologe. 2015 Apr;55(4):337-48.

14. Sharif HS, Clark DC, Aabed MY, Haddad MC, al Deeb SM, Yaqub B, et al. Granulomatous spinal infections: MR imaging. Radiology. 1990;177(1):101-7.

15. Jarvik JG, Deyo RA. Diagnostic evaluation of low back pain with emphasis on imaging. Ann Intern Med. 2002;137(7):586-97.

16. Hong SH, Choi J-Y, Lee JW, Kim NR, Choi J-A, Kang HS. MR imaging assessment of the spine: infection or an imitation? Radiographics. 2009;29(2):599-612.

17. Lee KY. Comparison of pyogenic spondylitis and tuberculous spondylitis. Asian Spine J. 2014;8(2):216-23.

18. Sembrano JN, Polly DW. How often is low back pain not coming from the back? Spine (Phila Pa 1976). 2009;34(1):E27-32. 